\title{
ANÁLISE MICROBIOLÓGICA DE MATÉRIAS PRIMAS E FORMULAÇÕES FARMACÊUTICAS MAGISTRAIS
}

\author{
Microbiological analysis of raw materials and pharmaceutical formulations
}

\author{
Flávia R. O. Andrade ${ }^{1}$; Aline A. Souza ${ }^{1}$; Maria do Carmo B. Arantes ${ }^{1}$; José R. de Paula ${ }^{1}$; \\ Maria T. F. Bara ${ }^{1^{*}}$ \\ ${ }^{1}$ Laboratório de Controle de Qualidade de Medicamentos, Faculdade de Farmácia, Universidade Federal de Goiás. \\ Praça Universitária s/n. 74605-220. Goiânia-GO, Brasil.
}

*Autor para correspondência. e-mail: mbara@farmacia.ufg.br

Recebido em 05/02/2005 - Aceito em 16/11/2005

RESUMO: De acordo com as Boas Práticas em Farmácia, os produtos farmacêuticos devem possuir qualidade compatível com especificações determinadas por códigos oficiais, visando assegurar seu uso. A qualidade microbiológica da matéria-prima empregada nas formulações de medicamentos e cosméticos é fator primordial para se alcançar eficiência e segurança. Neste trabalho, realizou-se a contagem de bactérias heterotróficas e pesquisa de Escherichia coli, coliformes totais e fecais em amostras de água destilada, deionizada e obtidas por osmose reversa. Realizou-se também a contagem de microrganismos aeróbios viáveis totais (bactérias e fungos), a pesquisa de bactérias patogênicas e de coliformes totais em amostras de matérias-primas vegetais e produtos naturais; e em formulações-bases de cremes, loções e géis. O método aplicado e as especificações foram baseados em Farmacopéias ou nos dados da Organização Mundial de Saúde. Os resultados obtidos evidenciaram que 86,3\% das amostras analisadas se encontravam em conformidade com os padrões estabelecidos. A qualidade microbiológica da água deionizada demonstrou que esta constitui um problema a ser solucionado nas farmácias com manipulação, sendo verificado que $65 \%$ das amostras estavam com limites de carga microbiana acima das especificações. Na análise das formulações básicas de produtos magistrais semi-acabados verificou-se que $97,17 \%$ estavam de acordo com limites estabelecidos. Em relação às matérias-primas vegetais e demais produtos naturais, $3,51 \%$ e $10,5 \%$, respectivamente, estavam em desacordo com as especificações. Os dados obtidos mostraram que as Boas Práticas de Manipulação em Farmácias contribuíram para a melhoria da qualidade microbiológica de produtos farmacêuticos magistrais, entretanto, verificou-se um ponto crítico a ser solucionado, que é a qualidade da água purificada por deionização.

PALAVRAS - CHAVE: controle de qualidade microbiológico; água deionizada; matéria-prima vegetal; produtos farmacêuticos semi-acabados.

ABSTRACT: In agreement with Good Manufacturing Practice, pharmaceutical products must have a quality
according to specifications set by official compendia assuring their use. The microbiological quality of raw material
employed in pharmaceutical and cosmetic formulations is very important to achieve efficacy and safety. In this work it
was done the heterotrophic bacteria count, the total viable aerobic count, yeasts and moulds count, detection of
pathogenic bacteria in samples of purified water, plant raw materials, natural products and in formula base of creams,
lotions and gels. The applied methods and the specifications were based on Pharmacopeas or World Health
Organization. The results showed that $86.3 \%$ of analysed samples were according to the parameters. The
microbiological quality of deionizated water demonstrated a problem to pharmacies and it was verified that $65 \%$ of
them were above the specifications. It was found that $97.17 \%$ of the formulations were with microbial counts in the
permited limit. The plant raw materials and natural products showed values of $3.51 \%$ and $10.5 \%$, respectively in
disagreement with the specifications. The obtained data demonstrated that the Good Manufacturing Practice applied to 
pharmacies contribute to microbiological quality of the pharmaceutical products, however, critical points must be solved, as the quality of the deionizated water used must be improved.

KEYWORDS: microbiological quality control; pharmaceutical products; vegetable raw material; deionizated water.

\section{INTRODUÇÃO}

O uso seguro e eficaz de medicamentos e cosméticos envolve análises físico-químicas e microbiológicas de matérias-primas e do produto acabado, como etapa preliminar para alcançar um padrão de qualidade necessário aos mesmos.

A Farmácia Magistral representa um importante segmento do mercado farmacêutico brasileiro. A Anvisa (BRASIL, 2000), por meio da Resolução 33/2000, instituiu as Boas Práticas de Fabricação em Farmácia, buscando estabelecer rígidos parâmetros de qualidade em todas as etapas de fabricação de um produto manipulado de forma magistral. Em conformidade com a legislação, as farmácias têm implantado ou terceirizado ensaios físico-químicos e microbiológicos.

Em relação ao controle de qualidade microbiológico de produtos não estéreis, nos quais admite-se a presença de carga microbiana limitada, o objetivo imediato desta análise é comprovar a ausência de microrganismos patogênicos e determinar o número de microrganismos viáveis, em função da utilização do produto, por exemplo para uso tópico ou oral. Deve-se ressaltar que carga microbiana elevada pode comprometer a estabilidade do produto, conseqüentemente, pode haver perda da eficácia terapêutica, por degradação do princípio ativo ou por alteração de parâmetro físico fundamental para a sua atividade, como o pH. Além disso, alterações das propriedades físicoquímicas também podem afetar a ação terapêutica, comprometendo a biodisponibilidade do produto e a aceitação do mesmo pelo consumidor. Variações de pH podem resultar em faixas de coloração distintas do corante ou em precipitações; produção de gases, provocando odor desagradável; ação enzimática promovendo degradação de tensoativos (lipases) ou macromoléculas (celulases), levando à quebra de emulsões ou alterações da viscosidade de géis (PINTO et al., 2000).

O controle de qualidade microbiológico de matérias-primas, medicamentos e cosméticos tem sido abordado em diversos trabalhos (DE LA ROSA et al, 1995; JIMENEZ, 2001; SCHWARB et al., 2001; CORREA e MIRANDA, 2002; FREGONEZI-NERY et al., 2002; AMARAL e VILELA, 2003; ROCHA et al, 2004; ZARONI et al, 2004). A qualidade de matérias-primas farmacêuticas, como lactose, amido, talco, goma arábica e adragante, gelatina e celulose foi investigada por DE LA ROSA et al. (1995), que demonstraram a presença de bactérias dos gêneros Enterobacter, Serratia e Proteus em diversos excipientes analisados. As gomas foram os produtos com maiores níveis de contaminação bacteriana e fúngica. A qualidade microbiológica de produtos para uso tópico foi demonstrada por SCHWARB et al., 2001, que relataram a necessidade de maiores estudos sobre conservantes para estas formulações, para prevenir a contaminação por agentes causadores de micoses, como Paecilomyces lilacinus. FREGONEZI-NERY et al. (2002) verificaram que por meio da análise sensorial de formulações de albendazol, na forma de suspensão, pode-se inferir sobre a qualidade deste medicamento, uma vez que alterações na aparência, odor e sabor da mesma foram observadas, embora o conteúdo de albendazol tenha permanecido inalterado.

Uma matéria-prima que merece especial atenção devido ao amplo uso em formulações farmacêuticas e cosméticas é a água, a qual também é utilizada em diferentes tipos de limpeza e operações unitárias nas farmácias (PINTO et al, 2000). Pode receber tratamento de purificação distinto conforme a aplicação que se deseja, sendo os métodos mais utilizados, destilação e deionização. Deionização tem sido muito usado, principalmente frente à economia nos gastos com água e energia em relação à destilação. A pureza da água está relacionada à ausência de patógenos e a uma carga mínima de microrganismos não patogênicos, estabelecidos pela UNITED STATES PHARMACOPEIA (2000); BRITISH PHARMACOPOEA (2000); AMERICAN PUBLIC HEALTH ASSOCIATION (1995). Estudos realizados por CORREA e MIRANDA (2002) e DINIZ (2000), demonstraram a necessidade de um rigoroso controle de qualidade microbiológico da água para evitar contaminação microbiana nos produtos acabados. Na análise microbiológica da água para fins farmacêuticos, têm-se como limites de aceitação em termos de contagem padrão em placas de bactérias heterotróficas, não mais que $10^{2}$ UFC $/ \mathrm{mL}$ (UNITED STATES PHARMACOPEIA, 2000), coliformes totais: <1,1 NMP / 100 mL e ausência de coliformes termotolerantes (AMERICAN PUBLIC HEALTH ASSOCIATION, 1995); ausência de E. coli, P. aeruginosa e de S. aureus (BRITISH PHARMACOPOEA, 2000).

Plantas medicinais e produtos naturais são componentes ativos ou adjuvantes farmacotécnicos de diversas formas farmacêuticas magistrais. A determinação da carga microbiana em plantas medicinais e matérias-primas vegetais é um parâmetro que contribui para a segurança e qualidade de fitoterápicos (BRASIL, 2004). Estudos realizados por SANTOS et al. (1995); KNEIFEL et al. (2002) e ROCHA et al. (2004) investigaram e constataram uma considerável contaminação microbiana em plantas medicinais. A contaminação de plantas medicinais por Escherichia coli e fungos aflatoxigênicos tem sido relatada na literatura (VEIGA JUNIOR e PINTO, 2005). Ações preventivas têm 
sido citadas visando diminuir a contaminação microbiana de plantas, por meio de processos de qualificação de fornecedores de matérias-primas, onde procedimentos de boas práticas agrícolas, especialmente relacionadas aos processos de colheita, secagem e armazenamento recebem destaque (DALL'AGNOL, 2001). Na análise de medicamentos contendo matérias-primas vegetais, baseados no tipo de uso das mesmas, os limites permitidos para carga microbiana são (WORLD HEALTH ORGANIZATION, 1998):

a) Para aquelas matérias-primas que serão submetidas a tratamento que pode conduzir a uma redução do número de microrganismos antes do uso, como por exemplo, com água fervente: microrganismos aeróbios viáveis (totais): $\leq 10^{7}$ bactérias aeróbias e $\leq 10^{5}$ fungos $/ \mathrm{g}$ ou $/ \mathrm{mL} ; E$. coli: $\leq 10^{2} / \mathrm{g}$ ou $\mathrm{mL}$.

b) Outras preparações vegetais: microrganismos aeróbios viáveis (totais): $\leq 10^{5}$ bactérias aeróbias e $\leq 10^{4}$ fungos/ $\mathrm{g}$ ou / mL; enterobactérias e outras bactérias gram-negativas: $\leq 10^{3} / \mathrm{g}$ ou $/ \mathrm{mL}$; ausência de E. coli e de Salmonella.

Em relação aos demais produtos naturais, como produtos de origem marinha (algas e ostra), produtos nãobioativos de origem vegetal (amido) e produtos de origem animal (gelatina e lactose), as especificações estabelecidas determinam que medicamentos para administração por via oral contendo matérias-primas de origem natural tenham como limite de aceitação, em termos de microrganismos aeróbios viáveis totais, não mais que $10^{4}$ bactérias aeróbias e não mais que $10^{2}$ fungos $/ \mathrm{g}$ ou $\mathrm{mL}$; ausência de Salmonella, de E. coli e de S. aureus (FARMACOPÉIA BRASILEIRA, 1988).

A análise microbiológica de preparações cosméticas para uso tópico, amplamente elaboradas nas farmácias magistrais, visa assegurar o uso destes produtos. Uma formulação magistral pode veicular microrganismos indesejáveis provenientes da água empregada, de outras matérias-primas presentes na mesma, dos manipuladores, do ambiente, da embalagem, dentre outros. Cosméticos têm como limites de aceitação, em termos de microrganismos aeróbios viáveis totais, não mais que $10^{3} \mathrm{UFC} / \mathrm{g}$ ou $\mathrm{mL}$, sendo o limite máximo de $5 \times 10^{3} \mathrm{UFC} / \mathrm{g}$ ou ml; ausência de $P$. aeruginosa, S. aureus e coliformes totais e fecais (BRASIL, 1999).

Diante do exposto, o objetivo deste trabalho foi determinar o número de UFC / $\mathrm{g}$ ou $\mathrm{mL}$ (unidades formadoras de colônias) em matérias-primas e produtos semi-acabados em amostras enviadas por farmácias ao Laboratório de Controle de Qualidade Microbiológico da Faculdade de Farmácia da UFG. A investigação da qualidade dos produtos analisados visou contribuir para a melhoria da qualidade dos mesmos.

\section{MÉTODOS}

\section{Amostras analisadas:}

Neste trabalho foram analisadas 135 matérias-primas, incluindo água e 106 formulações farmacêuticas (produtos semi-acabados), totalizando-se 241 amostras.

Foram analisadas amostras de água destilada (20), água deionizada (37), água obtida por osmose reversa (02), matérias-primas vegetais (57, sendo: cáscara sagrada pó: 08; castanha da Índia pó: 13; extrato seco de ginkgo biloba: 10; guaraná em pó: 08; garcinia: 03; extrato seco de hipérico: 01; espinheira santa pó: 02; boldo pó: 01; artemísia pó: 01; maracujá pó: 01; sene pó: 02; Citrus aurantium : 03; pata de vaca pó: 01; alcachofra: 01; centela: 01; hamamelis pó: 01); e produtos naturais (19, sendo: cálcio de ostra: 03; espirulina: 03; fucus: 07; clorela: 01; amido de milho: 02; gelatina: 01; lactose: 02). Também foram analisadas formulações bases de cremes (lanette: 23; polowax: 14; croda: 04; paramul: 04; "cold cream": 01; fotoprotetor: 12), loção lanette (10) e de géis (carbopol: 21; natrosol: 14; géis para uso em exames clínicos tipo ultrasson: 03).

As amostras foram enviadas por Farmácias com Manipulação de Goiânia-GO e região, no período de fevereiro de 2002 a abril de 2005.Todas as amostras estavam dentro do prazo de validade e as amostras foram coletadas conforme instruções adequadas e em frascos esterilizados. Para execução das análises microbiológicas, coletaram-se $200 \mathrm{~mL}$ da água proveniente da saída do equipamento.

\section{Contagem de microrganismos aeróbios viáveis totais em matérias-primas vegetais, produtos naturais e formulações farmacêuticas (produtos semi-acabados):}

Foram pesados $10 \mathrm{~g}$ de cada amostra, que foram diluídas em $90 \mathrm{ml}$ de caldo caseína-soja (Merck) ou caldo caseína lecitina peptona polissorbato, respectivamente para matérias-primas vegetais ou formulações farmacêuticas. Após homogeneização, foram realizadas diluições decimais sucessivas, sendo semeados em profundidade 1,0 mL de cada diluição para meio de cultura agar caseína-soja (MercK) e agar Sabouraud dextrose (Difco) (FARMACOPÉIA BRASILEIRA, 1988). As placas foram incubadas a $37^{\circ} \mathrm{C} / 3$ dias (bactérias) e $25^{\circ} \mathrm{C} / 7$ dias (fungos). Após a incubação, realizou-se a contagem de colônias (UFC/g). As amostras que apresentaram crescimento foram submetidas a ensaios para pesquisa de patógenos (Escherichia coli, coliformes totais e fecais), conforme descrito na FARMACOPÉIA BRASILEIRA, 1988. 


\section{Contagem de bactérias heterotróficas viáveis:}

A contagem de bactérias heterotróficas em amostras de água foi realizada transferindo $10 \mathrm{~mL}$ de água a ser analisada para 10 tubos de cultivo $(19 \times 1 \mathrm{~cm})$ contendo $10 \mathrm{~mL}$ de caldo lactosado duplo (MercK), com tubo de Durham. Transferiu-se 1,0 mL da água para placas de petri em duplicada, sendo acrescentados $20 \mathrm{~mL}$ de meio de cultura agar Caseína-soja (MercK). Em seguida, os tubos e as placas foram incubados a $37^{\circ} \mathrm{C}$ por $48 \mathrm{~h}$, para então, realizar-se a contagem de colônias (UFC/mL) (UNITED STATES PHARMACOPEIA, 2000). As amostras que apresentaram crescimento bacteriano foram submetidas a ensaios presuntivos para presença de coliformes totais, nos quais transferiram-se, com o auxilio de alça de platina, alíquotas do meio caldo lactosado para meio de cultura caldo verde brilhante (MercK) e incubou-se a $37^{\circ} \mathrm{C}$ por $24 \mathrm{~h}$. Os tubos que apresentaram formação de gás foram submetidos ao teste confirmativo para a presença de coliformes termotolerantes (fecais). Para tanto, alíquotas provenientes do meio caldo verde brilhante, que apresentaram crescimento, foram transferidas, com o auxilio de alça de platina para tubos de cultivo de $19 \times 1 \mathrm{~cm}$ contendo caldo Escherichia coli (Merck). O meio de cultura foi incubado em banho-maria à $44^{\circ} \mathrm{C}$, por $24 \mathrm{~h}$ e os tubos que apresentaram desenvolvimento de gás confirmaram a presença de coliformes termotolerantes (AMERICAN PUBLIC HEALTH ASSOCIATION, 1995). As amostras que apresentaram contagem de bactérias heterotróficas acima dos limites permitidos foram investigadas quanto à presença de $P$. aeruginosa e de S. aureus (BRITISH PHARMACOPOEA, 2000).

\section{RESULTADOS E DISCUSSÃO}

Os resultados obtidos neste trabalho evidenciaram que das 241 amostras analisadas, $86,3 \%$ encontravam em conformidade com os padrões estabelecidos.

Em relação à análise microbiológica da água para fins farmacêuticos, verificou-se que das 59 amostras analisadas, 44\% estavam em desacordo com as especificações farmacopêicas (Gráficos 1 e 2). Dentre as amostras reprovadas, detectou-se problemas em duas amostras de água destilada e 24 amostras de água deionizada, cujos valores da contagem padrão de bactérias heterotróficas variaram de 1,2 a 2,3 × $10^{3} \mathrm{UFC} / \mathrm{g}$. Pode-se verificar que das 37 amostras de água deionizada, 65\% estavam acima dos limites permitidos. Bastonetes gram-positivos nãofermentadores de lactose foram encontrados na maioria das amostras reprovadas. Foi detectada a presença de 01 amostra de água deionizada contaminada com E. coli. A qualidade microbiológica da água deionizada demonstrou que esta etapa do processo de produção constitui um problema a ser solucionado nas farmácias com manipulação. A saturação da resina do deionizador, a manutenção inadequada do equipamento e da caixa d’água podem maximizar os problemas detectados. Um dos principais fatores associados à alteração da qualidade da água e a redução da eficiência dos processos de tratamento é a proliferação de microorganismos. Independente do processo utilizado, o desenvolvimento de biofilmes pode ocorrer, dependendo da qualidade da água de alimentação e do regime de operação do sistema de tratamento (RIEDEWALD, 1997; PINTO et al., 2000).Outro fator que deve ser avaliado quanto à prevenção da contaminação microbiana é o armazenamento da água purificada, uma vez que esta é altamente susceptível ao desenvolvimento de microorganismos. Desta forma, quanto maior for o período de armazenamento, maior a possibilidade de ocorrer contaminação. De acordo com a RDC 33 (BRASIL, 2000), o período máximo de armazenagem da água purificada é de 24 horas. Modelos de deionizadores, com lâmpadas de radiação ultra-violeta acopladas à resina trocadora de íons têm sido usados visando uma ação germicida. A avaliação periódica da qualidade da água produzida pelas farmácias e a correta manutenção dos purificadores pode contribuir para a se alcançar os padrões de qualidade estabelecidos.

Dentre as matérias-primas vegetais analisadas, cuja maioria é destinada à fabricação de cápsulas, os resultados obtidos neste estudo demonstraram que das 57 amostras analisadas, somente 3,51\% estavam em desacordo com as especificações farmacopêicas (Gráficos 1 e 2). Dentre as amostras reprovadas, detectou-se problemas em uma amostra de garcínia e uma de citrus, cujos valores da contagem de aeróbios viáveis totais em

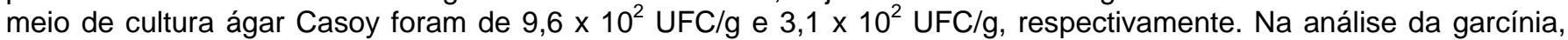
detectou-se a presença de bastonetes gram-positivos. Em relação aos dados encontrados nas análises das matériasprimas vegetais, os resultados permitem sugerir uma melhoria na qualidade microbiológica de plantas medicinais empregadas na produção de fitoterápicos, quando comparado com trabalhos de ROCHA et al (2004), que demonstraram uma baixa qualidade de amostras de sene e boldo. Também com trabalhos de ZARONI et al. (2004), que demonstram que $79 \%$ de amostras de plantas cultivadas não atendiam aos parâmetros da OMS para contagem total de aeróbios viáveis e SANTOS et al. (1995), que detectaram a presença de bactérias patogênicas como $P$. aeruginosa e $S$. aureus em $37,2 \%$ das amostras de plantas analisadas. Níveis elevados de aflatoxinas foram detectados em plantas medicinais por KNEIFEL et al. (2002). Processos de redução da carga microbiana, por meio de radiação gama $\left(\mathrm{Co}^{60}\right)$ têm sido descritos para amostras de plantas medicinais, o que pode está contribuindo para a melhoria de sua qualidade microbiológica (DALL'AGNOL, 2001). 
Medicamentos para administração por via oral contendo matérias-primas de origem natural também foram investigados neste estudo. Os resultados obtidos demonstraram que dos 19 produtos analisadas, 10,5\% estavam em desacordo com a especificação farmacopêica (Gráficos 1 e 2). Das amostras reprovadas nas análises, detectou-se problemas em duas amostras de cálcio de ostra, cujos valores da contagem de aeróbios viáveis totais foram $1,2 \times 10^{5}$ e $3 \times 10^{5} \mathrm{UFC} / \mathrm{g}$. Foram encontrados bastonetes gram-positivos em uma das amostras de cálcio de ostra. A qualidade microbiológica de lactose, amido, talco, goma arábica e adragante, gelatina e celulose foi investigada por DE LA ROSA et al. (1995), que verificaram a presença de bactérias patogênicas como Enterobacter, Serratia e Proteus nas gomas.

$\mathrm{Na}$ análise dos produtos semi-acabados, ou seja, formulações-bases de cremes, loções e géis verificou-se que das 106 formulações analisadas, somente 2,83\% estavam em desacordo com as especificações, portanto, $97,17 \%$ das amostras foram aprovadas nesta análise farmacêutica (Gráficos 1e 2). Dentre as amostras reprovadas, detectou-se problemas em três amostras de géis, sendo um à base de carbopol, um de natrosol e um gel manipulado para uso em ultrassonografias, não sendo especificado sua composição. Bastonetes gram-positivos nãofermentadores de lactose foram encontrados nestas amostras, os quais podem estar relacionados à contaminação ambiental ou serem provenientes de materiais, da água utilizada ou de pessoal não paramentado. A qualidade microbiológica de produtos para uso tópico foi investigada por SCHWARB et al., 2001, que detectaram a contaminação por agentes causadores de micoses, como Paecilomyces lilacinus.

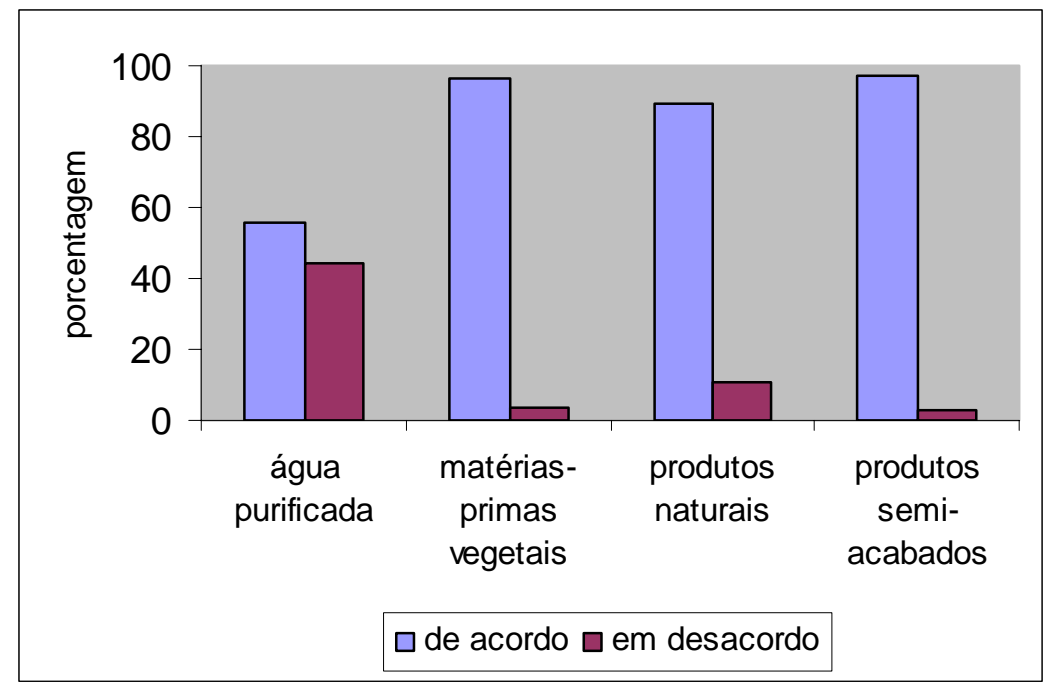

Gráfico 1. Avaliação da qualidade microbiológica de matérias-primas e produtos magistrais semi-acabados.

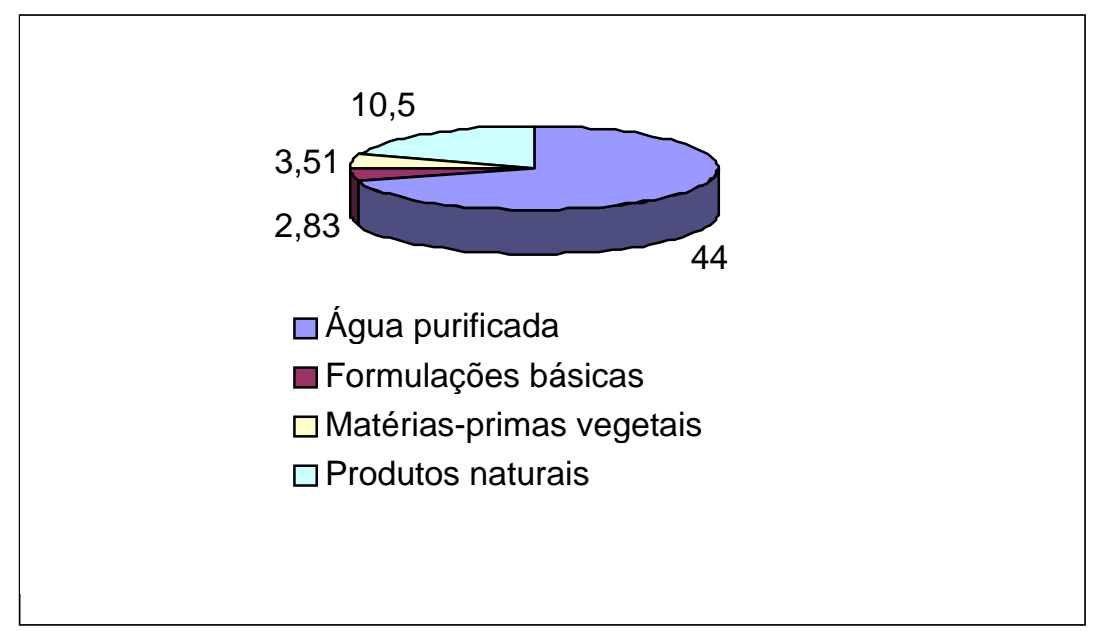

Gráfico 2. Porcentagem de matérias-primas e produtos farmacêuticas semi-acabadas em desacordo com as especificações estabelecidas para as análises microbiológicas. 
Esta avaliação microbiológica apresentou uma grande relevância no sentido de indicar parâmetros de qualidade de produtos farmacêuticos elaborados por farmácias magistrais. Por meio das análises microbiológicas, aliadas às análises físico-químicas, pode-se contribuir para garantir a eficácia e segurança de produtos farmacêuticos.

\section{CONCLUSÕES}

Os dados obtidos mostraram que as Boas Práticas em Farmácia, instituídas pela RDC 33/ 2000 (BRASIL, 2000) certamente contribuíram muito para a qualidade de formas farmacêuticas magistrais. Entretanto, um ponto crítico a ser solucionado, é a melhoria da qualidade microbiológica da água purificada por deionização usada nas farmácias. Pode-se sugerir, como medida preventiva deste problema a sanitização e manutenção adequada do equipamento, o uso de água de boa qualidade antes da entrada do deionizador, o uso de água recém purificada, o uso de equipamentos contendo lâmpadas germicidas, ligadas intermitentemente e a avaliação periódica da qualidade microbiológica da água.

\section{REFERÊNCIAS BIBLIOGRÁFICAS}

AMARAL, M. P. H.; VILELA, M. A. P. Controle de Qualidade na Farmácia de Manipulação. $2^{a}$ Edição. Juiz de Fora: Editora da UFJF/ Ômega Editora e Distribuidora Ltda., 2003.

AMERICAN PUBLIC HEALTH ASSOCIATION. Standard methods for the examination of water and wastewater. 19th ed. Washington, p. 9-48. 1995.

BRASIL, Ministério da Saúde. Agência Nacional de Vigilância Sanitária. Resolução 33 de 19 de abril de 2000. Regulamento técnico que institui as boas práticas de manipulação em farmácias. Brasília,2000.

BRASIL. Ministério da Saúde. Agência Nacional de Vigilância Sanitária. Resolução 48 de 16 de março de 2004. Registro de Medicamentos Fitoterápicos. Brasília, 2004.

BRASIL. Ministério da Saúde. Agência Nacional de Vigilância Sanitária. Resolução 481 de 23 de setembro de 1999. Controle de qualidade microbiológico para os produtos de higiene pessoal, cosméticos e perfumes. Brasília, 1999.

BRITISH PHARMACOPOEA, v.II, Strasbourg: Council of Europe. 2000.

CORREA, A.M.; MIRANDA, C. A. A. Análise dos sistemas de purificação e controle de qualidade da água utilizada em farmácias de manipulação de Joinville.44 p. Trabalho de Conclusão de Curso. Univille. Joinvile. 2002.

DALL'AGNOL, L. Avaliação dos Efeitos da Radiação Gama $\left(\mathrm{Co}^{60}\right)$ sobre princípios ativos e carga microbiana de plantas medicinais. Revista Brasileira de Plantas Medicinais. v.3, n.2, p. 45-51, 2001.

DE LA ROSA, M.C.; MEDINA, M.R.; VIVAR, C. Microbiological quality of pharmaceutical raw materials. Pharmaceutica Acta Helvetiae. v.70, n. 3, p. 227 - 232. 1995.

DINIZ, D. G. A. Avaliação da Qualidade da Água Purificada em Farmácias de Manipulação em Goiânia-GO. 42 p. Trabalho de Conclusão de Curso. UFG. Goiânia. 2000.

FARMACOPÉIA BRASILEIRA: 4ª edição. parte 1. São Paulo: Editora Atheneu, 1988.

FREGONEZI-NERY, M. M.; PRUDENCIO-FERREIRA, S.H.; KEDOR, E.M.R.; BARACAT, M.M.; BRINHOLI, F.F. Sensory evaluation of albendazole suspensions. Brazilian Archives of Biology and Technology. v. 45, n. 4, p. $457-$ 463. dec. 2002.

JIMENEZ, L. Rapid methods for the microbiological surveillance of pharmaceuticals. Journal of Pharmaceutical Science Technology. v. 55, n. 5, p. 278 - 285. sep / oct. 2001.

KNEIFEL, W.; CZECH, E.; KOPP, B. Microbial contamination of medicinal plants. A review. Planta Medica. v. 68, p. 5 15, 2002. 
PINTO, T.J.A; KANEKO, T.M.; OHARA, M.T. Controle biológico de qualidade de produtos farmacêuticos, correlatos e cosméticos. São Paulo: Atheneu, 2000. p. 75-96.

RIEDEWALD,F. Biofilms in Pharmaceutical Waters. Pharmaceutical Engineering. v.17, n. 6, 1997.

ROCHA, L.O; SOARES, M.M.S.R.; CORÊA, C.L. Análise da contaminação fúngica em amostras de Cassia acutifolia Delile (sene) e Peumus boldus (Molina) Lyons (boldo-do-Chile) comercializadas na cidade de Campinas, Brasil. Revista Brasileira de Ciências Farmacêuticas. v. 40, n. 4, p. 521 - 527. out / dez, 2004

SANTOS, P. R. V; OLIVEIRA, A.C.X.; TOMASSINI, T.C.B. Controle microbiológico de produtos fitoterápicos. Revista de Farmácia e Bioquímica. v. 31, n. 1, p. 35-38. jan./ jun. 1995.

SCHWARB, F.P.; GABARD, B.; BIELI, E.; SCHWARB, S.; SURBER, C. Microbiological quality of topical drug formulations: efficacy of antimicrobial preservation against Paecilomyces lilacinus. Dermatology. v. 203, n. 3, p. 248 255. 2001.

UNITED STATES PHARMACOPEIA (USP). 24th edithion, NF 20, S2, Rockville: Twinbrook Parkway, p. 2163. 2000

VEIGA JUNIOR, V.F.; PINTO, A.C. Plantas medicinais: cura segura? Química Nova. v. 28, n. 3, p. 519 - 528. 2005.

WORLD HEALTH ORGANIZATION (WHO). Quality control methods for medicinal plants materials. Geneva: WHO, 1998.

ZARONI, M.; PONTAROLO, R.; ABRAHÂO, W.S.M.; FÁVERO, M.L.D.; CORREA JÚNIOR, C.; STREMEL, D.P. Qualidade microbiológica das plantas medicinais produzidas no Estado do Paraná. Revista Brasileira de Farmacognosia. v.14, n.1, p. 29 - 39, jan.-jun., 2004. 